\title{
UNDERSTANDING TRANSITORY RAINFALL SHOCKS, ECONOMIC GROWTH AND CIVIL CONFLICT
}

\author{
Edward Miguel \\ Shanker Satyanath \\ Working Paper 16461 \\ http://www.nber.org/papers/w16461
NATIONAL BUREAU OF ECONOMIC RESEARCH
1050 Massachusetts Avenue
Cambridge, MA 02138
October 2010

The views expressed herein are those of the authors and do not necessarily reflect the views of the National Bureau of Economic Research.

NBER working papers are circulated for discussion and comment purposes. They have not been peerreviewed or been subject to the review by the NBER Board of Directors that accompanies official NBER publications.

(C) 2010 by Edward Miguel and Shanker Satyanath. All rights reserved. Short sections of text, not to exceed two paragraphs, may be quoted without explicit permission provided that full credit, including (C) notice, is given to the source. 
Understanding Transitory Rainfall Shocks, Economic Growth and Civil Conflict

Edward Miguel and Shanker Satyanath

NBER Working Paper No. 16461

October 2010

JEL No. N47,O55,Q54

\begin{abstract}
$\underline{\text { ABSTRACT }}$
Miguel, Satyanath and Sergenti (2004) use rainfall variation as an instrument to show that economic growth is negatively related to civil conflict in sub-Saharan Africa. In the reduced form regression they find that higher rainfall is associated with less conflict. Ciccone (2010) claims that this conclusion is 'erroneous' and argues that higher rainfall levels are actually linked to more conflict. In this paper we show that the results in Ciccone's paper are based on incorrect STATA code, outdated conflict data, a weak first stage regression and a questionable application of the GMM estimator. Leaving aside these data and econometric issues, Ciccone's surprising results do not survive obvious robustness checks. We therefore conclude that Ciccone's main claims are largely incorrect and reconfirm the original result by Miguel, Satyanath and Sergenti (2004), finding that adverse economic growth shocks, driven by falling rainfall, increases the likelihood of civil conflict in sub-Saharan Africa.
\end{abstract}

\author{
Edward Miguel \\ Department of Economics \\ University of California, Berkeley \\ 508-1 Evans Hall \#3880 \\ Berkeley, CA 94720 \\ and NBER \\ emiguel@econ.berkeley.edu \\ Shanker Satyanath \\ Department of Politics \\ New York University \\ 19 West 4th Street \\ New York, NY 10012 \\ shanker.satyanath@nyu.edu
}




\section{Introduction}

The paper "Transitory Economic Shocks and Economic Conflict" by Antonio Ciccone (2010) examines the effects of shifts in rainfall levels on civil conflict in sub-Saharan Africa. The paper is presented as a contribution building on the previous work of Miguel, Satyanath, and Sergenti (2004, henceforth MSS) that addressed the question of whether poor economic performance has a causal effect on civil conflict in sub-Saharan Africa. Using rainfall variation as an instrumental variable for economic growth, MSS find that growth is strongly negatively related to civil conflict: a negative growth shock of five percentage points increases the likelihood of civil conflict in the next year by nearly one half.

Ciccone replicates the methodology by MSS but uses rainfall levels (rather than rainfall growth) as instruments for economic growth. Rainfall levels had also been examined by MSS, as they noted on page 734 of their paper. They mention, however, that the first stage is considerably weaker when using rainfall levels instead of rainfall growth.

In the reduced form regression of civil conflict on rainfall growth, MSS find that higher rainfall growth is associated with significantly less conflict. Using various definitions of civil conflict, the coefficient on lagged rainfall growth (in year t-1) is negative and statistically significant. Ciccone's paper focuses primarily on this reduced form relationship and uses current and lagged rainfall levels (in logs) as the explanatory variables. As opposed to the findings in MSS, Ciccone claims that higher rainfall levels are associated with more civil conflict. In the regression of conflict on log rainfall levels, he finds that the coefficient on the second lag of log rainfall (in year t-2) is sometimes positive and statistically significant. Based on this reduced form relationship, he concludes that the earlier results by MSS are "erroneous” and “unwarranted”.

We recognize Ciccone's (2010) contribution in starting a new conversation around regression functional form issues when estimating the economic causes of civil conflict, and believe this is an interesting and potentially constructive direction for future research. However, the empirical evidence that Ciccone presents does not convincingly back up his claims.

In this brief note, we closely examine Ciccone's analysis and show that his central claim about the positive relationship between lagged rainfall and conflict is largely incorrect. His erroneous findings are based on incorrect STATA code and the questionable use of a GMM estimator, and his main results no longer hold when these issues are addressed. We also show that most of Ciccone's results fail to hold in several obvious robustness checks.

Moreover, the analysis underlying Ciccone's central claim is based on outdated data and he acknowledges that these older data contain coding errors (p. 11). Using the most recent extended and 
corrected data, Ciccone admits that he finds a strong, negative impact of t-1 lagged rainfall on civil conflict across multiple specifications and no significant effect of t-2 lagged rainfall, which is in line with the original findings in MSS. Ciccone does not elaborate on this inconsistency in his analysis and instead opts to focus on the outdated data in drawing his conclusions; we believe that civil war scholars (like Ciccone and ourselves) should focus on the most recent - and corrected - conflict data as it is released, rather than spending considerable time on outdated data series. We replicate Ciccone's analysis using the most recent dataset, which shows that the reduced form between rainfall and conflict merely confirms the earlier results in MSS, while Ciccone's main claim no longer holds. In addition to the reduced form relationship, we show that an instrumental variables approach confirms MSS's finding that civil conflict is more likely to follow negative economic growth shocks in sub-Saharan Africa.

\section{Estimation Framework and Data}

In the first stage, MSS study the relationship between rainfall variations and economic growth:

$$
\text { growth }_{\mathrm{it}}=\mathrm{a}_{1 \mathrm{i}}+\mathrm{X}_{\mathrm{it}}^{\prime} \mathrm{b}_{1}+\mathrm{c}_{1,0} \Delta \mathrm{R}_{\mathrm{it}}+\mathrm{c}_{1,1} \Delta \mathrm{R}_{\mathrm{i}, \mathrm{-t}-1}+\mathrm{d}_{1 \mathrm{i}} \text { year }_{\mathrm{t}}+\mathrm{e}_{1 \mathrm{it}}
$$

Economic growth in country $\mathrm{i}$ in year $\mathrm{t}$ is measured by per capita GDP. Rainfall variation is captured by current and lagged rainfall growth $\left(\Delta \mathrm{R}_{\mathrm{i}, \mathrm{t}}\right.$ and $\left.\Delta \mathrm{R}_{\mathrm{i}, \mathrm{t}-\mathrm{l}}\right)$. MSS experimented with a variety of instruments for economic growth, including rainfall levels and deviations from mean rainfall levels. Although results are similar amongst these measures, current and lagged rainfall growth give the strongest first stage relationship and were thus the focus of the article. Country characteristics $\left(\mathrm{X}_{\mathrm{it}}\right)$ are controlled for, and country fixed effects $\left(\mathrm{a}_{\mathrm{i}}\right)$ and country-specific time trends $\left(\mathrm{d}_{\mathrm{i}} \mathrm{year} \mathrm{r}_{\mathrm{t}}\right)$ are included to capture additional variation. $\mathrm{e}$ is the disturbance term.

To establish the relationship between economic growth and conflict, MSS carry out the following second stage analysis:

$$
\text { conflict }_{\mathrm{it}}=\alpha_{2 \mathrm{i}}+\mathrm{X}_{\mathrm{it}}^{\prime} \beta_{2}+\gamma_{2,0} \text { growth }_{\mathrm{it}}+\gamma_{2,1} \text { growth }_{\mathrm{i}, \mathrm{t}-1}+\delta_{2 \mathrm{i}} \text { year }_{\mathrm{t}}+\varepsilon_{2 \mathrm{it}}
$$

Data on civil conflict comes from UCDP/PRIO and several indicators of conflict can be distinguished. The variable of interest can be either conflict incidence or conflict onset. The conflict incidence indicator equals one if the country is in conflict that year. In order to distinguish between conflict outbreak and continuation, the variable conflict onset is used to refer only to conflict outbreak. MSS show that their results hold using all these conflict indicators.

Ciccone's first stage analysis using rainfall levels at time t, t-1 and t-2 is given by:

$$
\text { growth }_{i t}=a_{1 i}+X_{i t}^{\prime} b_{1}+c_{1,0} \log \left(R_{i, t}\right)+c_{1,1} \log \left(R_{i, t-1}\right)+c_{1,2} \log \left(R_{i, t-2}\right)+d_{1 i} y e_{t}+e_{1 i t}
$$


The second stage analysis is similar to the one used by MSS, but with slightly different measures and with an additional lag term:

$$
\begin{array}{r}
\text { conflict }_{\mathrm{it}}=\alpha_{2 \mathrm{i}}+\mathrm{X}_{\mathrm{it}}^{\prime} \beta_{2}+\gamma_{2,0} \log \left(\text { growth }_{\mathrm{it}}\right)+\gamma_{2,1} \log \left(\text { growth }_{\mathrm{i}, \mathrm{t}-1}\right)+ \\
\gamma_{2,2} \log \left(\text { growth }_{\mathrm{i}, \mathrm{t}-2}\right)+\delta_{2 \mathrm{i}} \text { year }_{\mathrm{t}}+\varepsilon_{2 \mathrm{it}}
\end{array}
$$

\section{Robustness Checks on Ciccone (2010)}

This section focuses on Ciccone's claims in his Tables 1 through 4, which uses outdated data, and shows that his main claims are not robust. The next section (section IV) uses the most recent updated conflict data, and we show that his main claim again fails to hold with this data, as he himself acknowledges (on page 11).

Ciccone (2010) argues that positive rainfall shocks are associated with more armed conflict and presents two initial tables supporting this claim (Table 1 and Table 2 of his paper). According to Ciccone, these tables prove that the negative coefficient on t- 1 rainfall growth found by MSS turns into a positive coefficient on t-2 rainfall levels. In this section we investigate the validity and robustness of this finding, the central claim in Ciccone (2010). We follow Ciccone in focusing on the 25 battle deaths threshold.

Ciccone begins by replicating MSS's results, using rainfall growth as the key explanatory variable. In the first column of his Table 1, Ciccone replicates MSS's reduced form regression of conflict onset on current and lagged rainfall growth (time t and t-1), resulting in a significant negative coefficient on lagged rainfall growth measures. In the next column, he casts doubt on MSS's results by inexplicably excluding current rainfall growth and instead using two lags of rainfall growth (time t-1 and t-2). According to Ciccone, the negative coefficient on $\mathrm{t}-1$ rainfall growth has disappeared and there is a significant positive coefficient on t-2 rainfall growth. Ciccone argues that this regression implies that civil conflict onset is more likely following positive rainfall shocks.

We first examine the validity of this provocative claim. A careful look at Ciccone's STATA do-file (posted on his website during June to October 2010, while we worked on this discussion) reveals that he uses the STATA command 'ivreg2' in this analysis. This alarmed us since the command 'regress' ought to be used for an ordinary least squares regression, such as this one, while the 'ivreg2' command is meant for regression analysis involving instrumental variables. Email conversations with online STATA support confirmed that ivreg2 is not the correct command for an OLS regression. Furthermore, they pointed out that Ciccone uses the ivreg command in an incorrect manner, which is likely to reduce reported standard errors and thus exaggerate statistical significance. ${ }^{1}$ We replicated

\footnotetext{
${ }^{1}$ When sharing Ciccone's Stata code with a senior statistician from Stata Technical Support, he explains: 'The output for -ivreg2- contains a warning on the estimated covariance Matrix. [The warming is]... certainly
} 
Ciccone's analysis using the correct STATA command and find that the positive point estimate on t-2 rainfall growth is no longer statistically significant at the traditional 90 percent confidence level. This can be seen by comparing columns 1 and $1 \mathrm{~b}$ in Table R1. ${ }^{2}$

Table R1: Robustness Checks of the Regression of Civil Conflict Onset on Rainfall Shocks

\begin{tabular}{|c|c|c|c|c|}
\hline \multirow{7}{*}{ Explanatory Variable } & \multicolumn{4}{|c|}{ Dependent Variable: Conflict Onset $\geq 25$ Death } \\
\hline & \multirow{7}{*}{$\begin{array}{c}(1) \\
\text { Ciccone } \\
\text { Table } 1 \\
\text { Column } 2 \\
\text { Sta } \\
\text { “ivreg2” }\end{array}$} & (1b) & \multirow[t]{6}{*}{$(2)$} & \multirow[t]{6}{*}{ (3) } \\
\hline & & & & \\
\hline & & & & \\
\hline & & & & \\
\hline & & nd: & & \\
\hline & & “regress" & & \\
\hline \multirow[t]{2}{*}{ Rainfall Growth, t } & & & -0.061 & -0.069 \\
\hline & & & {$[0.058]$} & [0.057] \\
\hline \multirow[t]{2}{*}{ Rainfall Growth, t-1 } & -0.04 & -0.04 & -0.076 & -0.087 \\
\hline & [0.048] & [0.051] & {$[0.070]$} & {$[0.071]$} \\
\hline \multirow{2}{*}{ Rainfall Growth, t-2 } & $0.087 *$ & 0.087 & 0.063 & 0.054 \\
\hline & [0.051] & {$[0.056]$} & [0.063] & [0.063] \\
\hline Country fixed effects & yes & yes & yes & yes \\
\hline Country-specific time trends & yes & yes & yes & yes \\
\hline Country-specific controls & no & no & no & yes \\
\hline Observations & 521 & 521 & 521 & 521 \\
\hline R-squared & 0.42 & 0.42 & 0.422 & 0.427 \\
\hline
\end{tabular}

Note. - Huber robust standard errors are in parentheses. Regression disturbance terms are clustered at the country level. A country-specific year time trend in included in all columns (coefficient estimates not reported). The country-specific control variables are Democracy (Polity IV) t-1 and Log(national population) t-1.

* Significantly different from zero at 90 percent confidence

** Significantly different from zero at 95 percent confidence

*** Significantly different from zero at 99 percent confidence

Column 1: replication Ciccone Table 1, Column 2, using incorrect ‘ivreg2' STATA command

Column 1B: similar to Ciccone Table 1, Column 2, using correct 'regress' STATA command

Column 2: similar to Ciccone Table 1, Column 2, including rainfall growth at time $t$

Column 3: similar to Ciccone Table 1, Column 2, including rainfall growth at time $t$ and control variables

Apart from using incorrect STATA code, it is also surprising that Ciccone excludes rainfall growth in the current period (t) in his main specification in column 1 above. Confirming our doubts about Ciccone's approach, when we add this explanatory variable again into column 2, the positive coefficient on t-2 rainfall growth once again fails to reach traditional confidence levels (and the tstatistic=1.0). In column 3 we add time-varying political and demographic control variables and again Ciccone's central result disappears, this time with a t-statistic less than one. We conclude that the significant positive coefficient on t-2 rainfall growth that Ciccone (2010) reports is erroneous, and is

indicating that the presence of collinearity is affecting the rank of the variance-covariance matrix in the computations implemented by-ivreg2-. Based on the results that you are getting, I would emphasize that you should rather use -regress- to fit models via OLS.' Furthermore, the Stata Technical Support representative explains that Ciccone uses the ivreg2 command incorrectly: 'You need to specify the "small" option in the command line for -ivreg2-; otherwise, the degrees of freedom adjustment would be different.' Ciccone does not do this. When re-doing Ciccone's analysis correctly using the 'small' option, his results are no longer statistically significant, which is also the case using the 'regress' command (as shown in our Table R1). ${ }^{2}$ Since 'regress' is the correct STATA command for OLS, we use it for the remainder of this paper. 
the result of using an incorrect STATA regression command and picking out an unusual regression specification.

The remaining two columns in Ciccone's Table 1 (cols 3-4) show positive and significant coefficient estimates on "Log Rainfall, t-2", but as we show below (in our Table R3), as Ciccone himself acknowledges, these results disappear with corrected and updated conflict data.

In Ciccone's Table 2, he uses conflict incidence as the dependent variable instead of conflict onset and again claims to find a positive coefficient on t-2 rainfall shocks. However, a simple OLS regression of conflict incidence on rainfall levels at time t, t-1 and t-2 does not yield a significant positive coefficient on lagged rainfall. This can be seen in column 1 of Table R2 (equivalent to column 6 in Ciccone's Table 2).

However, Ciccone does not elaborate on this OLS finding with conflict incidence as the dependent variable in his paper, and instead uses a system-GMM estimate in cols 2-5 of his Table 2, which yields a positive point estimate on the second lag of rainfall levels. Ciccone argues that the use of the GMM estimator is required because of the inclusion of a lagged dependent variable along with country fixed effects. However, this GMM approach is not actually required or even advisable in the current empirical context since the number of time periods $(\mathrm{T}$ ) is relatively large (at 19 periods, 19811999). It is well known that the "Nickell bias" that GMM estimation is designed to address disappears when the number of time periods becomes sufficiently large. As we show below a) our results are robust to allowing for the likely Nickell bias in OLS, and b) Ciccone's results are not robust to the use of OLS, and his results for conflict incidence only hold when this particular GMM estimator is used. Rather than focusing on a more standard and robust econometric approach, Ciccone (2010) focuses on a specification with weak econometric justification but which yields the positive point estimate on lagged rainfall that he emphasizes, and never mentions the OLS evidence in his own Table 2.

It is possible to gauge the extent of the Nickell (1981) bias in OLS specifications that include the lagged dependent variable along with fixed effects. The extent of Nickell bias is a function of $\mathrm{T}$, and it rapidly falls to well below $10 \%$ for $\mathrm{T}>15$ in our case. The precise formula, derived by Nickell (1981) is given by $\operatorname{plim}_{N \rightarrow \infty}(\hat{\gamma}-\gamma) \cong \frac{-(1+\gamma)}{T-1}$, where $\gamma$ is the relationship between the dependent variable in period $\mathrm{t}$ and period $\mathrm{t}-1$. In our case, $\mathrm{T}=19$ and $\gamma=0.28$. Therefore, the Nickell bias for the lagged dependent variable term is roughly equal to $\frac{-(1+0.28)}{19-1}=-0.071$. This bias of $7 \%$ is quite small. Nickel (1981) did not work out the extent of bias for specifications with other explanatory variables, but a large literature in econometrics and in political science has since used Monte Carlo methods to show that the bias on other explanatory variables is likely to be smaller still. For instance, Judson and 
Owen (1999) estimate that the bias on other explanatory variables (such as our rainfall terms in this application) in a setting with $\mathrm{T}=20$ periods could be closer to $1 \%{ }^{3}$

In this context of essentially non-existent Nickell bias, it is hard to justify the use of GMM, with its strong identification assumptions and questionable finite sample properties, in place of much more transparent and robust OLS estimation.

As Table R2 shows, the positive coefficient on $\mathrm{t}-2$ rainfall shocks is not found using OLS (and would continue to be nearly unchanged even after correcting point estimates by 1 to $7 \%$ for any potential Nickell bias). Table R2 starts in the first two columns by using log rainfall levels following Ciccone as a measure of rainfall shocks and shows that there is not a statistically significant positive coefficient estimate on the lagged t-2 rainfall measure. This is the case with and without lagged conflict incidence as a control variable (columns 1 and 2). Ciccone also carries out the analysis with rainfall growth as a proxy for rainfall variation. After replicating MSS's results, he again inexplicably leaves out rainfall growth in the current time period and only includes the first two lags of rainfall growth, while still using the questionable GMM estimator. We replicate this analysis using OLS in columns 3 and 4 (with and without lagged conflict incidence as a control variable) and find a significant negative point estimate on t-1 rainfall growth, which is in line with MSS's original results. These results are also found in columns 5 and 6 when we again include current time rainfall growth. Even allowing for Nickell bias does not threaten the robustness of this result given a likely magnitude of only 1 to $7 \%$. Robustness checks in columns 7 and 8 , involving the addition of control variables as listed in Table R1, again fail to find positive effects of rainfall growth in t-2.

\footnotetext{
${ }^{3}$ Other recent work that is critical of the use of GMM methods when there exists at least a moderate number of time periods (T) includes Papaioannou and Siourounis (2008, Economic Journal) and Wilson and Butler (2007, Political Analysis), among others.
} 
Table R2: Robustness Checks of the Regression of Civil Conflict Incidence on Rainfall Shocks (Using OLS)

\begin{tabular}{|c|c|c|c|c|c|c|c|c|}
\hline \multirow[b]{2}{*}{ Explanatory Variable } & \multicolumn{8}{|c|}{ Dependent Variable: Conflict Incidence $\geq 25$ Death } \\
\hline & $(1)$ & $(2)$ & (3) & $(4)$ & (5) & (6) & (7) & (8) \\
\hline & $\begin{array}{c}\text { Ciccone } \\
\text { Table } 2 \\
\text { Column } 6 \\
\text { using OLS } \\
\end{array}$ & $\begin{array}{c}\text { Ciccone } \\
\text { Table } 2 \\
\text { Column } 4 \\
\text { using OLS } \\
\end{array}$ & & $\begin{array}{c}\text { Ciccone } \\
\text { Table } 2 \\
\text { Column } 3 \\
\text { using OLS } \\
\end{array}$ & & & & \\
\hline \multirow{2}{*}{ Log Rainfall, $\mathrm{t}$} & -0.076 & -0.062 & & & & & & \\
\hline & [0.065] & [0.073] & & & & & & \\
\hline \multirow[t]{2}{*}{ Log Rainfall, t-1 } & -0.115 & -0.074 & & & & & & \\
\hline & {$[0.076]$} & [0.077] & & & & & & \\
\hline \multirow[t]{2}{*}{ Log Rainfall, $t-2$} & 0.110 & 0.124 & & & & & & \\
\hline & [0.079] & [0.074] & & & & & & \\
\hline \multirow{2}{*}{ Rainfall Growth, t } & & & & & -0.033 & -0.027 & -0.026 & -0.023 \\
\hline & & & & & [0.051] & {$[0.049]$} & [0.051] & [0.049] \\
\hline \multirow[t]{2}{*}{ Rainfall Growth, t-1 } & & & $-0.099 * *$ & $-0.089 *$ & $-0.118^{*}$ & $-0.105^{*}$ & -0.103 & $-0.097 *$ \\
\hline & & & {$[0.049]$} & [0.049] & {$[0.064]$} & {$[0.057]$} & {$[0.063]$} & {$[0.056]$} \\
\hline \multirow[t]{2}{*}{ Rainfall Growth, t-2 } & & & 0.001 & 0.029 & -0.011 & 0.019 & 0.000 & 0.024 \\
\hline & & & {$[0.039]$} & {$[0.040]$} & {$[0.046]$} & {$[0.046]$} & [0.045] & {$[0.045]$} \\
\hline Lagged Conflict & & $0.276^{* * *}$ & & $0.280 * * *$ & & $0.280 * * *$ & & $0.276^{* * *}$ \\
\hline Incidence & & {$[0.089]$} & & [0.088] & & {$[0.088]$} & & [0.089] \\
\hline Country fixed effects & yes & yes & yes & yes & yes & yes & yes & yes \\
\hline $\begin{array}{l}\text { Country-specific time } \\
\text { trends }\end{array}$ & yes & yes & yes & yes & yes & yes & yes & yes \\
\hline $\begin{array}{l}\text { Country-specific } \\
\text { Controls }\end{array}$ & no & no & no & no & no & no & yes & yes \\
\hline Observations & 743 & 702 & 702 & 702 & 702 & 702 & 702 & 702 \\
\hline R-squared & 0.709 & 0.733 & 0.711 & 0.733 & 0.711 & 0.733 & 0.713 & 0.734 \\
\hline
\end{tabular}

Note. - Huber robust standard errors are in parentheses. Regression disturbance terms are clustered at the country level. A country-specific year time trend in included in all specification (coefficient estimates not reported). The country-specific control variables are Democracy (Polity IV) t-1 and Log(national population) t-1.

* Significantly different from zero at 90 percent confidence

** Significantly different from zero at 95 percent confidence

*** Significantly different from zero at 99 percent confidence

Table R2 replicates part of Ciccone’s Table 2 using OLS instead of GMM.

Column 1: replication Ciccone Table 2, Column 6

Column 2: similar to Ciccone Table 2, Column 4 using OLS

Column 3: similar to Ciccone Table 2, Column 3 using OLS without lagged conflict incidence

Column 4: similar to Ciccone Table 2, Column 3 using OLS

Column 5: similar to Ciccone Table 2, Column 3 using OLS, including rainfall growth at time t and without lagged conflict incidence

Column 6: similar to Ciccone Table 2, Column 3 using OLS, including rainfall growth at time t

Column 7: similar to Ciccone Table 2, Column 3 using OLS, including rainfall growth at time t and control variables and without lagged conflict incidence

Column 8: similar to Ciccone Table 2, Column 3 using OLS, including rainfall growth at time t and control variables

Thus carefully reviewing Ciccone's main empirical results leads us to the conclusion that his claims are greatly overstated given the evidence, relying on a combination of: incorrect application of

STATA commands, unusual econometric specifications, and questionable application of GMM 
methods. We next explore the robustness of Ciccone's central claim to the most recent updated conflict data.

\section{Robustness to the Most Recent Conflict Data}

Ciccone (2010) focuses on data covering the period 1981 to 1999, as in MSS. At the time of writing his article, an extended dataset on civil conflict that included data through 2007 was available, but he used this extended dataset only for two regressions (in table 5 in his paper). This is surprising as Ciccone acknowledges that the older, outdated conflict dataset includes coding errors (page 11).

It is important to note that the two regressions using the most recent and corrected data do not support the central claims made throughout Ciccone (2010). In fact, the significant positive coefficient estimate on the t-2 rainfall lag once again disappears using the updated data. Ciccone briefly acknowledges that "this result turns into a significantly negative effect of $t-1$ rainfall once I use the latest (corrected) conflict data." (page 11) This is fully in line with the earlier findings by MSS (2004). Ciccone does not elaborate on this discrepancy and instead performs his main analysis using only the outdated data.

Table R3 replicates the reduced form analysis of conflict onset and incidence on rainfall shocks using the updated, corrected and extended data. Column 1 uses conflict onset as the dependent variable, while columns 2 through 5 use conflict incidence. In all specifications, the significant positive point estimate on t-2 lagged rainfall disappears. This is the case when using rainfall levels (columns 1, 2 and 3) as well as rainfall growth (columns 4-5) as measures of rainfall shocks. Furthermore, this statement holds irrespective of whether or not lagged conflict incidence is included as a control variable (columns 2 and 4). All significant coefficients are now negative as they are in MSS (2004) indicating that conflict is associated with negative rainfall shocks. This table shows once more that Ciccone (2010)'s central claim no longer holds with updated data. 
Table R3: Regression of Civil Conflict Incidence on Rainfall Shocks Using the Most Recent Conflict Data

\begin{tabular}{|c|c|c|c|c|c|}
\hline \multirow[t]{2}{*}{ Dependent Variable } & \multirow{2}{*}{$\begin{array}{c}\begin{array}{c}\text { Conflict Onset } \\
\geq 25 \text { Death }\end{array} \\
\text { (1) }\end{array}$} & \multicolumn{4}{|c|}{ Conflict Incidence $\geq 25$ Death } \\
\hline & & $(2)$ & (3) & (4) & (5) \\
\hline Explanatory Variable & $\begin{array}{c}\text { Ciccone } \\
\text { Table } 5 \\
\text { Column } 1 \\
\text { using OLS } \\
\end{array}$ & $\begin{array}{c}\text { Ciccone } \\
\text { Table } 5 \\
\text { Column } 2 \\
\text { using OLS } \\
\end{array}$ & & & \\
\hline Log Rainfall, t & $\begin{array}{c}0.041 \\
{[0.048]}\end{array}$ & $\begin{array}{c}-0.002 \\
{[0.044]}\end{array}$ & $\begin{array}{c}-0.034 \\
{[0.052]}\end{array}$ & & \\
\hline Log Rainfall, t-1 & $\begin{array}{c}-0.098^{* *} \\
{[0.047]}\end{array}$ & $\begin{array}{c}-0.125^{* *} \\
{[0.048]}\end{array}$ & $\begin{array}{c}-0.136 * * \\
{[0.051]}\end{array}$ & & \\
\hline Log Rainfall, t-2 & $\begin{array}{c}0.049 \\
{[0.038]}\end{array}$ & $\begin{array}{c}0.041 \\
{[0.051]}\end{array}$ & $\begin{array}{c}-0.008 \\
{[0.060]}\end{array}$ & & \\
\hline Rainfall Growth, t & & & & $\begin{array}{c}-0.006 \\
{[0.034]}\end{array}$ & $\begin{array}{c}-0.013 \\
{[0.043]}\end{array}$ \\
\hline Rainfall Growth, t-1 & & & & $\begin{array}{c}-0.122 * * \\
{[0.049]}\end{array}$ & $\begin{array}{c}-0.121 * \\
{[0.061]}\end{array}$ \\
\hline Rainfall Growth, t-2 & & & & $\begin{array}{c}-0.081 * * \\
{[0.039]}\end{array}$ & $\begin{array}{c}-0.111 * * \\
{[0.049]}\end{array}$ \\
\hline Lagged Conflict Incidence & & $\begin{array}{c}0.393 * * * \\
{[0.071]}\end{array}$ & & $\begin{array}{c}0.393 * * * \\
{[0.069]}\end{array}$ & \\
\hline Country fixed effects & yes & yes & yes & yes & yes \\
\hline Country-specific time trends & yes & yes & yes & yes & yes \\
\hline Observations & 825 & 1032 & 1073 & 1032 & 1032 \\
\hline R-squared & 0.235 & 0.668 & 0.609 & 0.669 & 0.61 \\
\hline
\end{tabular}

Note. - Huber robust standard errors in parentheses. Regression disturbance terms are clustered at the country level. A country-specific year time trend in included in all specification (coefficient estimates not reported).

* Significantly different from zero at 90 percent confidence

** Significantly different from zero at 95 percent confidence

*** Significantly different from zero at 99 percent confidence

Table R3 replicates Ciccone’s Table 5 (using the most recent data)

Column 1: similar to Ciccone Table 5, Column 1 using OLS

Column 2: similar to Ciccone Table 5, Column 2 using OLS

Column 3: similar to Ciccone Table 5, Column 2, without lagged conflict incidence (OLS)

Column 4: similar to Ciccone Table 5, Column 2, using rainfall growth instead of rainfall levels (OLS)

Column 5: similar to Ciccone Table 5, Column 2, using rainfall growth instead of rainfall levels and without lagged conflict incidence (OLS)

Note that the results presented in Table R3 are based on OLS, which we prefer over GMM as discussed in the previous section. We also replicated these analyses using the updated conflict data and the GMM estimator and come to the same conclusion: all positive coefficients on lagged rainfall that Ciccone found with the old data have disappeared (results not shown). In fact, these lagged rainfall coefficients have negative point estimates using the updated data, which is again in line with the earlier findings of MSS (2004).

Ciccone goes on to claim that "instrumental-variables estimates did not yield a robust link between transitory income shocks and conflict” (page 12) even using the latest conflict data, although he does 
not report any of these results in the paper. However, when we carry out this analysis using the updated data, we find that this claim is incorrect. Our Table R4 presents a regression close to MSS (2004)'s preferred specification in column 1, and finds that GDP growth in both t and t-1 are strongly negatively related to civil conflict incidence at $95 \%$ and $99 \%$ confidence, respectively, and with point estimates similar to MSS (2004). In Ciccone’s preferred specification in column 2, none of the lagged log GDP terms have a significant relationship with conflict, in part because of very large standard errors in these IV estimates.

Table R4: IV Results Using Most Recent Data GDP Growth, GDP, and Civil Conflict (Second Stage)

\begin{tabular}{|c|c|c|}
\hline \multirow{3}{*}{ Explanatory Variable } & \multicolumn{2}{|c|}{$\begin{array}{c}\text { Dependent variable: } \\
\text { Conflict Incidence } \geq 25 \text { Death }\end{array}$} \\
\hline & (1) & (2) \\
\hline & $\begin{array}{c}\text { Ciccone } \\
\text { Table 3, Column } 2 \\
\text { with most recent data }\end{array}$ & $\begin{array}{c}\text { Ciccone } \\
\text { Table 3, Column } 3 \\
\text { with most recent data }\end{array}$ \\
\hline \multirow[t]{2}{*}{ GDP Growth, t } & $-2.33^{* *}$ & \\
\hline & [1.17] & \\
\hline \multirow[t]{2}{*}{ GDP Growth, t-1 } & $-2.30^{* * *}$ & \\
\hline & {$[0.76]$} & \\
\hline \multirow[t]{2}{*}{ Log GDP, $\mathrm{t}$} & & -0.93 \\
\hline & & [2.20] \\
\hline \multirow{2}{*}{ Log GDP, t-1 } & & -0.83 \\
\hline & & [1.08] \\
\hline \multirow[t]{2}{*}{ Log GDP, $t-2$} & & 1.73 \\
\hline & & [2.93] \\
\hline \multirow[t]{2}{*}{ Lagged Incidence } & $0.29^{* * *}$ & 0.31 \\
\hline & {$[0.067]$} & {$[0.20]$} \\
\hline Country fixed effects & yes & yes \\
\hline Country-specific time trends & yes & yes \\
\hline Observations & 1032 & 1032 \\
\hline
\end{tabular}

Note. - Huber robust standard errors are in parentheses. Regression disturbance terms are clustered at the country level. A country-specific year time trend in included in all specification (coefficient estimates not reported).

* Significantly different from zero at 90 percent confidence

** Significantly different from zero at 95 percent confidence

*** Significantly different from zero at 99 percent confidence

Note that Ciccone uses GDP with the HP filter. We attempted to obtain the equivalent GDP HP data from Ciccone extended through 2007 through direct communication with him (via email), as we were unable to replicate his exact construction of this series, but we have not yet heard back from him. Hence we opt to use GDP. Results using GDP and GDP HP filtered data for the period through 1999 are quite similar (not shown).

Column 1: replication Ciccone Table 4, Column 2 using the most recent data

Column 2: replication Ciccone Table 4, Column 3 using the most recent data

We turn to the first stage relationships to investigate the source of these large standard errors. In Table R5 column 1 we present a regression analogous to a first stage (although not exactly the first stage since there are multiple endogenous variables), with rainfall growth in t and t-1 as the instrumental variables, as in MSS (2004), and show that both IV's are significant at over 99\% confidence, with a 
decent F-statistic of joint significance of 6.79. In column 2 we present the first stage for Ciccone’s preferred rainfall measures, Log Rainfall in time t, t-1 and t-2, and we find that two of the three are not significant at traditional confidence levels, one is significant at $90 \%$ confidence, and the F-statistic is a very weak 2.06. IV's with this weak an F-statistic are known to lead to incorrectly sized statistical tests (Stock and Yogo 2002, Dufour 1997), suggesting that IV estimation using Ciccone’s preferred measures and regression specification is unlikely to be reliable. Thus Ciccone’s claim (on page 12) that IV estimates do not show a strong link between transitory economic shocks and civil conflict using the latest data appears unfounded.

Table R5: IV First stage relationships using the most recent conflict data

\begin{tabular}{lcc}
\hline \hline & \multicolumn{2}{c}{ Dependent variable: } \\
Explanatory Variable & GDP growth & Log GDP \\
\hline Rainfall Growth, t & $0.031^{* * *}$ & $(2)$ \\
Rainfall Growth, t-1 & {$[0.010]$} & \\
& $0.029^{* * *}$ & \\
Log Rainfall, t & {$[0.009]$} & \\
& & 0.038 \\
Log Rainfall, t-1 & & $0.0275]$ \\
& & $0.0480^{*}$ \\
Log Rainfall, t-2 & & {$[0.0245]$} \\
& & $\mathbf{0 . 0 2 5 1}$ \\
Country fixed effects & & {$[\mathbf{0 . 0 2 9 4}]$} \\
Country-specific time trends & yes & yes \\
Observations & yes & yes \\
R-squared & 1073 & 1073 \\
F-statistic of joint significance & 0.13 & 0.978 \\
\hline
\end{tabular}

Note. - Huber robust standard errors in parentheses. Regression disturbance terms are clustered at the country level. A country-specific year time trend in included in all specification (coefficient estimates not reported).

* Significantly different from zero at 90 percent confidence

** Significantly different from zero at 95 percent confidence

*** Significantly different from zero at 99 percent confidence

Note that Ciccone uses GDP with the HP filter. We attempted to obtain the equivalent GDP HP data from Ciccone extended through 2007 through direct communication with him (via email), as we were unable to replicate his exact construction of this series, but we have not yet heard back from him. Hence we opt to use GDP as the dependent variable. Results using GDP and GDP HP filtered data for the period through 1999 are quite similar (not shown).

Column 1: first stage MSS using the most recent data

Column 2: first stage Ciccone using the most recent data

\section{Conclusion}

In this brief note, we review Antonio Ciccone's recent paper on rainfall, economic growth and civil conflict. Similar to Miguel, Satyanath and Sergenti (2004) he uses rainfall as an instrument to study the relationship between economic growth and civil conflict. Although MSS found in their reduced 
form regression that higher rainfall is associated with less conflict, Ciccone claims that this influential conclusion is 'erroneous'. He argues that higher lagged rainfall is actually associated with more conflict.

We recognize Ciccone's (2010) contribution in starting a new conversation around regression functional form issues when estimating the economic causes of civil conflict, and believe this is an interesting and potentially constructive direction for future research. However, the empirical evidence that Ciccone presents does not convincingly back up his claims.

After carefully replicating and reviewing Ciccone’s analysis, we conclude that his claims are largely erroneous and that his results are based on incorrect STATA code that exaggerates the statistical significance of his main coefficient estimate, unusual regression specification choices, the questionable application of the GMM estimator (in a context with a relatively large number of time periods where OLS is generally preferred), use of outdated conflict data, and a particularly weak first stage regression in his IV analysis. Furthermore, we show that Ciccone's results do not survive most of the robustness checks we carry out.

Ciccone performs most of his analysis using outdated data that contains coding errors, as he himself acknowledges. When carrying out the reduced form regression using the updated and corrected data, he admits that his claims no longer survive. Using the latest data and IV-2SLS methods we come to the same conclusion as MSS in 2004, namely that adverse economic growth shocks, driven by falling rainfall, greatly increase the likelihood of civil conflict in sub-Saharan Africa. 


\section{References}

Ciccone, Antonio. 2010. "Transitory Economic Shocks and Civil Conflict.”

http://www.antoniociccone.eu/wp-content/uploads/2010/02/transitory-shocks-february2010f.pdf. (downloaded October 1, 2010)

Canova, Fabio. 2007. Methods for Applied Macroeconomic Research. Princeton University Press, Princeton, NJ.

Dufour, Jean-Marie. 1997. “Some Impossibility Theorems in Econometrics With Applications to Structural and Dynamic Models.” Econometrica, 65, 1365-1387.

Judson, Ruth and Ann Owen. 1999. "Estimating Dynamic Panel Data Models: A Guide for Macroeconomists.” Economics Letters, 65 (1), 9-15.

Miguel, Edward, Shanker Satyanath, and Ernest Sergenti. 2004. "Economic Shocks and Civil Conflict: An Instrumental Variables Approach.” Journal of Political Economy, 112 (41): 725-753.

Nickell, Stephen. 1981. "Biases in dynamic models with fixed effects.” Econometrica 49, 1417-1426.

Papaioannou, Elias and Gregorios Siourounis. 2008. "Democratization and Growth.” Economic Journal, 118(532), 1520-1551.

Stock, James and Motohiro Yogo. 2002. “Testing for Weak Instruments in Linear IV Regression.” NBER Technical Working Paper No. 284.

Wilson, Sven, and Daniel Butler. 2007. "A lot more to do: The sensitivity of time-series-cross-section analyses to simple alternative specifications.” Political Analysis 15:101-23. 